\title{
Methods Used for Determining Nurse Downsizing: An Integrative Review
}

\author{
Kamyla Lameira Vieira', Janete de Souza Urbanetto², Ana Elizabeth Figueiredo',2 \\ ${ }^{1}$ Post Graduation Program in Medicine and Health Sciences, School of Medicine, Pontificia Universidade \\ Católica do Rio Grande do Sul, Porto Alegre, Brazil \\ ${ }^{2}$ School of Nursing, Nutrition and Physiotherapy, Pontifícia Universidade Católica do Rio Grande do Sul, Porto \\ Alegre, Brazil \\ Email: anaef@pucrs.br
}

Received 24 January 2015; accepted 8 February 2015; published 13 February 2015

Copyright $\odot 2015$ by authors and Scientific Research Publishing Inc.

This work is licensed under the Creative Commons Attribution International License (CC BY).

http://creativecommons.org/licenses/by/4.0/

(c) (i) Open Access

\begin{abstract}
The study aimed to look for available evidence in the literature regarding tools and methods used for determining nurse staffing levels. It is an integrative literature review whose data search was performed electronically between September and October 2013. The integrative review consisted of 13 articles that responded to the inclusion criteria proposed in the study. Several tools and methods were identified that determine staffing numbers, however, implementation of the calculated required workforce is not yet effective in the institutions surveyed.
\end{abstract}

\section{Keywords}

Downsizing Staff, Workload, Nursing

\section{Introduction}

Determination of nursing personnel levels help nurses through administrative instruments whose content assists in management of the nursing unit and that aim to predict, from a quantitative and qualitative approach, the number of nursing staff required to meet patient care needs [1].

An inadequate number of nurse staffing has the consequence of increasing the workload of these professionals, which may cause a rise in adverse events in patient care, such as the development of pressure ulcers, errors in medication administration and increasing hospital infections [2] [3].

Research carried out to assess the adequacy of the number of professionals in a health unit reported that increased workload tends to amplify the number of distractions and interruptions at work. Each interruption was associated with a $12 \%$ rise in failure to conduct procedures and in clinical errors committed by nurses. More 
than half the nurses said they were overloaded, and there was an increase in mistakes and omissions in medication administration made by these nurses [4].

Nurses, as a leader or manager of the nursing work process, needs tools that will help determine the required size of nursing staff, with a view to providing effective assistance and reducing work overload.

There are currently tools capable of quantifying workload, calculating the total number of nursing hours per patient, the percentage of hours spent nursing, and measuring the daily required number of nursing staff to assist patients. These methods are being increasingly used and are strategies to decrease the workload while meeting patient needs, in order to ensure effective care, decrease adverse events associated with high workload, and reduce the length of hospitalization as a result.

The Federal Nursing Council (COFEN, in Portuguese acronyms), through Resolution No. 293/04 (13), established minimum parameters for staffing levels required for care coverage in health institutions, based on characteristics related to the organization, the nursing service and the clientele [5].

The negative outcome of this context is associated with work overload, which makes the correct sizing of personnel necessary for ideal patient assistance. This leads to the question of this study: Which methods are used for determining numbers of nursing staff?

The aim of this study was to search the evidence available in the literature related to instruments and methods used for determining nurse staffing levels.

\section{Methods}

This is a descriptive study using an integrative review design, which consists of the construction of a wide analysis of the literature, contributing to the discussion on research methods and results, as well as reflection regarding the conduct of future studies. The initial purpose of this research method is to obtain a deep understanding of a given phenomenon, based on previous studies [6].

The six steps that make up an integrative literature revision were used. Firstly, the theme, objective and keywords according to the Descriptors in Health Sciences (DeCS, in Portuguese acronyms) were defined: staffing levels, workload and nursing.

The inclusion criteria were next established: articles published in the last ten years (2003-2013), Brazilian (Portuguese) and international articles (English and Spanish) available as a full version, without cost. The data was searched electronically using the Virtual Health Library (LILACS, BDENF, MEDLINE) and the period of search and selection occurred from September to October 2013.

After the articles were selected the studies were categorized, extracting the required information that was then organized and incorporated into a table. A database was created based on the information from the selected articles.

Subsequently, evaluation and critical analysis of the articles were conducted, and from this, the interpretation of the results, discussion and proposed recommendations were attained, ending with a synthesis of the knowledge and presentation of the literature review.

A summary table was designed to organize the selected study data, containing the following information: year of publication, authors, journal, country, study type, study design and method of staff sizing used.

\section{Results and Discussion}

Fifty-nine articles were found, with 14 of these repeated as they were published in two different databases; 7 articles did not fit the inclusion criteria related to year of publication (2003-2013); 5 were published in a language not included in this study; and 20 were not available as free full texts.

The integrative review consisted of 13 articles that responded to the inclusion criteria proposed in the study. They were organized in tables containing the article information, with a description of the sizing methods used in the studies. Thirteen original articles were found and are presented in Table 1.

The selected articles were all from Brazil and published between 2005 and 2013. There was a higher prevalence of studies of an exploratory descriptive style. The findings of these studies have been organized in Table 1 and will be discussed according to the methods employed.

Study 1 refers to use of the Nursing Activities Score (NAS) to determine the size of nursing staff in a neonatal unit. The NAS is used to quantify the nursing workload. It consists of 23 items, subdivided into the different categories: basic activities, ventilatory support, cardiovascular support, renal support, neurological support, 
Table 1. Identification of the included original articles and methods used for determining the size of staffing levels.

No. study/Author/Year/Country/Journal/Study design

1) Nunes, BK; Toma, E. 2013; Brazil; Revista Latino-Americana

de Enfermagem (Latin American Journal of Nursing); Exploratory study.

2) Fugulin, FNT, et al. 2012; Brazil; Revista Latino-Americana de Enfermagem (Latin American Journal of Nursing); Exploratory study.

3) Bem, LWD; Gaidzinski RR. 2007; Brazil; Revista da Escola de Enfermagem da USP (School of Nursing Journal, USP); Exploratory study.

4) Bonfim, D, et al. 2012; Brazil; Revista da Escola de Enfermagem da USP (School of Nursing Journal, USP); Exploratory study.

5) Gaidzinski, RR, et al. 2009; Brazil; Revista da Escola de Enfermagem da USP (School of Nursing Journal, USP); Methodological study.

6) Bordin, LC; Fugulin, FMT. 2009; Brazil; Revista da Escola de Enfermagem da USP (School of Nursing Journal, USP); Exploratory study.

7) Telles, SCR; Castilho, V. 2007; Brazil; LILACS; Revista Latino-Americana de Enfermagem (Latin American Journal of Nursing); Exploratory study.

8) Tranquitelli, AM; Ciampone, MHT. 2007; Brazil; Revista da Escola de Enfermagem da USP (School of Nursing Journal, USP); Exploratory study.

9) Costa, JA; Fugulin, FMT. 2010; Brazil; Acta Paulista de Enfermagem (Acta Paulista Nursing Journal); Methodological study.

10) Inoue, KC; Matsuda, LM. 2009; Brazil; Revista Eletrônica de Enfermagem (Nursing Electronic Journal); Exploratory study.

11) Wolff, LDG, et al. 2007; Brazil; Cogitare Enfermagem (Cogitare Nursing); Exploratory study.

12) Inoue, KC; Matsuda, LM. 2010; Brazil; Acta Paulista de Enfermagem (Acta Paulista Nursing Journal); Exploratory study.

13) Nicola, AL; Anselmi, ML. 2005; Brazil; Revista Brasileira de Enfermagem (Brazilian Journal of Nursing); Case study.

\section{Method of sizing}

Nursing Activities Score (NAS)

Patient Classification System (PCS)

Model proposal for calculating the size of nursing staff in home care (HC)

Interventions and classification survey according to the Nursing Interventions Classification (NIC) taxonomy

Computer program called Computerized Calculation of Nursing Professionals (Portuguese acronym, DIPE)

Distribution of time for tasks, classified by interventions according to the Nursing Interventions Classification (NIC) taxonomy

Therapeutic Intervention Scoring System (TISS-28)

Development of an instrument, in which the time for activities carried out by the nursing team were recorded, and then calculation applied to determine ideal size for the unit.

Identification of activities developed in a materials sterilization center (MSC) through a literature review and validated by experts specialized in the area.

Patient Classification System (PCS)

Nursing Activities Score (NAS)

Nursing Activities Score (NAS)

Perroca scale

metabolic support, and specific interventions. The NAS score represents the amount of work time (in percentage) that the patient required in the last 24 hours. Transforming this to the time of assistance given, each NAS point is equivalent to 14.4 minutes [7].

The sample size of this study comprised of 144 newborns (NB), divided in 5 sectors of the neonatal unit, and the instrument was applied 406 times throughout the unit. The isolation sector, composed of 13 patients and a daily staff of 12.22 was the place with more interference, in which the mean workload was 609.04 NAS points, with 85.74 ( $20 \mathrm{~h} 33 \mathrm{~min}$ ) per NB. According to NAS, the working staff per day should have been 30.43, which denoted a deficit of 18.21 people [7].

In study 11, the NAS was also applied to determine the nursing personnel size of a semi-intensive care unit in a university hospital. The instrument was administered to 96 hospitalized patients in the respective intensive care unit (ICU). The research showed that the professional staff for that area should be adjusted; according to the NAS, $41 \%$ more nursing professionals than currently existed would be needed to provide appropriate assistance to the patients in that ICU [8].

In study 12, the NAS was applied to 107 hospitalized patients in an ICU. As in the previous study, the findings showed an insufficient number of nursing professionals. According to the NAS, the mean was 697.3 points and there should be 40 nursing professionals to provide adequate staff coverage in this unit, although there were 
only 28. In relation to the category of nurses, the recommended proportion is $52.5 \%$, whereas the proportion found in the ICU was $35.7 \%$ [9].

Study 2 was conducted in an intensive care unit and the nursing assistance time was evaluated in accordance with parameters proposed by COFEN Resolution No. 293/04. The Patient Classification System (PCS) was used to calculate the personnel size. The time of care in hours per patient during a 24 hour period is proposed by this method of determining staffing levels, as well as the percentage distribution of professional nursing categories [5] [10].

The COFEN Resolution No. 293/04, in accordance with Article 4, established that, for calculation purposes, the nursing hours per patient bed in 24 hours should be considered as: 3.8 hours of nursing per client requiring minimal assistance or self-care; 5.6 hours of nursing per client when requiring intermediate care; 9.4 hours of nursing per client when requiring semi-intensive care; and 17.9 hours of nursing per client in intensive care [5].

With the percentage distribution of all the nursing professionals being established, the same resolution considered, in accordance with its Article $5^{\circ}$, that the percentage distribution of the total nursing professionals should observe the following proportions, as well as the PCS: for minimal to intermediate assistance $33 \%$ to $37 \%$ are nurses (minimum of six), with the others being auxiliary and/or technician nurses; for semi-intensive care $42 \%$ to $46 \%$ are nurses, with the others being auxiliary and/or technician nurses; for intensive care $52 \%$ to $56 \%$ are nurses, with the others being auxiliary and/or technician nurses [5].

The study of Fugulin et al. took place in ICUs of six hospitals in São Paulo. Nurses trained in the use of the instrument applied the PCS over a 20-day period during the morning shift. In all the ICUs studied, it was observed that the proportion of nurses was lower than that established by the COFEN Resolution No. 293/04, and the percentage of auxiliary/technician nurses was higher than indicated [10].

In study 10, the PCS was also used to establish the size of the nursing team of an adult ICU in a university hospital. It was applied to 65 patients over a period of 4 months. The number of professionals in this study was in accordance with the COFEN Resolution No. 293/2004, however, it was observed that the instrument does not identify all the activities performed in the ICU, with other areas meriting distinct consideration [11].

In study 13, determination of nursing staff numbers was performed in three inpatient medical and surgical specialty units. The Perroca Scale tool was used, which is the basis for the PCS. Data collection occurred over 92 days of observation, and the results obtained in the study revealed that the quantity of nursing professionals in the three units did not correspond with the number projected. In terms of the quantity of nurses, there were 27 in the institution, whereas according to the results the ideal number of nurses should be 28 . The number of nursing auxiliaries exceeded the amount proposed [12].

In study 3, based on the COFEN Resolution No. 293/04, which does not include the calculation of nursing professionals in outpatient clinics and homecare, a model was proposed to help determine the appropriate size for homecare assistance (HCA). A total of 48 professionals were interviewed who performed the function of HCA managers. These interviews allowed the construction of 3 categories to size the nursing staff: patient eligibility, time spent in caring and professional competency profile. Following analysis of the results of the statements, together with the experience of the author in HCA, calculations were developed that enabled the interrelationships of the variables influencing the staff sizing in HCA to be established [5] [13].

In study 4, the identification of nursing interventions in primary health care (PHC) was applied as a parameter for calculating the nursing staff. A literature review was conducted, followed by observation in a Family Health Unit (FHU) in the São Paulo region. The research subjects were 6 nurses and 9 auxiliary nurses. An evaluation of the nursing notes in patient medical records was randomly performed (32 family patient records) to detect the activities that were not identified in the literature review and by observation in loco [14].

After evaluation of the activities, a map of the nursing interventions was developed according to the Nursing Interventions Classification (NIC) taxonomy structure. It is organized on three levels, represented by domains, classes and interventions. The first level consists of seven domains (basic physiology, complex physiology, behavior, safety, family, and health and community system). The second level comprises of 30 classes distributed within the domains and the third level is formed of 514 nursing interventions [15].

The study identified 169 activities: 11 associated activities; 5 personal; and 153 related to direct and indirect care that were mapped and validated in 7 domains, 15 classes and 46 interventions of the NIC. Based on this classification, the article suggests the creation in other studies models of instruments used to identify nursing workload, as well as models to measure the time spent in caring interventions [14].

In study 6, the distribution of nursing time from a medical-surgical unit was performed through classification 
of the NIC activities and interventions. The evaluation of activity was carried out by the unit nurses and then classified according to the NIC interventions. Based on this, a data collection instrument was created and the nurses were observed during their work shift in order to quantify the nursing activities [16].

It was observed that $50 \%$ of the nursing time was dedicated to indirect care, such as documentation and supervision; $22 \%$ to direct care interventions; $18 \%$ to personal activities, and $10 \%$ to associated activities (not specific to nursing). The study showed that nurses from the health unit spent more time on indirect care than direct care related to patient assistance [16].

Study 5 was a technology production in which a web-based program was developed for calculating the size of the professional nursing team. The computer program is called Computerized Calculation of Nursing Professionals (DIPE, in Portuguese acronyms). This system was installed on the website of the School of Nursing, University of São Paulo (USP), at: http://www.ee.uso.br/dipe [17].

The system provides a projection of need of nursing professionals for hospital inpatient units. The data was interpreted based on the Gaidzinski method, in which the quantitative and qualitative nursing workload distribution calculation was used for an optimal ratio of nursing professionals/patients. The Technical Safety Index (IST, in Portuguese acronyms) is included in this calculation of estimated professionals to cover planned (days off and vacations) and unplanned time away from work (absences and leave of absence), and the time spent on breaks during working hours [17].

In study 7, the Therapeutic Intervention Scoring System (TISS-28) was used to identify the average time dedicated to patients and then to calculate the average daily cost of the direct nursing care provided to patients [18].

The TISS-28 was developed as a system that classifies the indirect severity of the patient, being based on the principle that the amount of therapeutic interventions that the patient undergoes is related to the severity of clinical case. It implies that the more severe the case, the higher the number of therapeutic interventions needed for treatment and, consequently, the greater the amount of time expended by the nurse for such care. The final score, which ranges from zero to a maximum of 76 points, enables an estimation to be made of both the interventions performed on the patient, and the size of the nursing workload [19].

The instrument was applied in an intensive care unit of a university hospital and the study sample consisted of 120 patients from that ICU, hospitalized during the period stipulated by the authors. A total of 722 measurements were carried out and the mean value of the TISS-28 per patient was 31 points. The mean time of daily nursing care was 133 hours, which corresponds to 251 points on the TISS-28, for a mean of 8.16 patients per day, considered high when compared to other studies [18].

In study 8, the mean time expended on direct activities for patients in an ICU at a private hospital was measured and then the mean hours calculated of direct nursing care for the hospitalized patients in this unit. All procedures performed were noted in patient records during the study period and then classified according to complexity: high, medium, low. After development of the instrument, it was applied and the nursing activities/ interventions noted, as well as an evaluation of the time expended to perform them [20].

All the procedures performed on 125 patients admitted to the ICU over the 3 month period formed a part of the study. The sizing method presented in the study is time consuming but gives an ideal estimation of the reality of the number of hours expended by nursing staff in the health unit involved [20].

Study 9 used the identification of activities developed in a materials sterilization center (MSC) as the method for assessing the nursing personnel size. The Delphi Technique was employed to validate the developed activities. To survey the actions carried out by these professionals working at the MSC, a literature review was first performed and, based on the results, a group of judges, experts in the field, conducted an assessment, and after some evaluations, the instrument was validated [21].

Six work areas were validated: 25 sub-processes, 110 activities and 25 activities specific to nursing. The study suggested that, based on the instrument and through knowledge of the activities, it is possible to estimate the time the professional expends to implement a task, helping to plan the appropriate professional staff for the MSC unit [21].

\section{Conclusions}

The proposed study, based on an integrative literature review, demonstrated that there are many formulas, tools and methods that can be used to determine the staffing levels of nursing professionals. In this sense, the presented studies enable establishment of the number of professionals based on health care needs. 
This aspect, however, has not had an effective impact on the daily management of nursing personnel. Although there is specific legislation related to this, the majority of studies showed deficits of professionals when the calculations related to professionals per patient were applied.

Some obstacles for the application of workforce sizing therefore remain, and this gap should be discussed in order to really improve health assistance, since, in 2013, the Brazilian Ministry of Health established the National Patient Safety Program, which establishes a series of requirements with the intention of reducing the occurrence of health care related adverse events to an acceptable minimum.

It cannot go unnoticed in this discussion that aims to qualify health assistance that, without determining the appropriate nursing personnel size, there is no possibility of guaranteeing this, and even less chance of assuring the safety of the professionals, leading to a decrease in workload, greater satisfaction, and as a consequence, better designed and safer care processes.

\section{References}

[1] Campos, L.F. and eMelo, M.R.A.C. (2009) Dimensionamento de pessoal de enfermagem: parâmetros, facilidades e desafios. Cogitare Enferm, 14, 237-246.

[2] Conishi, R.M.Ye. and Gaidzinski, R.R. (2007) Nursing Activities Score (NAS) como instrumento para medir carga de trabalho de enfermagem em UTI adulto. Revista da Escola de Enfermagem da USP, 41, 346-354. http://dx.doi.org/10.1590/S0080-62342007000300002

[3] Gonçalves, L.A. and Padilha, K.G. (2007) Fatores associados à carga de trabalho de enfermagem em Unidade de Terapia Intensiva. Revista da Escola de Enfermagem da USP, 41, 645-652. http://dx.doi.org/10.1590/S0080-62342007000400015

[4] Wolfe, W.A. (2011) Adequacy of Dialysis Clinic Staffing and Quality of Care: A Review of Evidence and Areas of Needed Research. American Journal of Kidney Diseases, 58, 166-176. http://dx.doi.org/10.1053/j.ajkd.2011.03.027

[5] BRASIL (2004) Conselho Federal de Enfermagem. Resolução no. 293/04. Fixa e estabelece parâmetros para dimensionamento do quadro de profissionais de enfermagem nas instituições de saúde. Conselho Regional de Enfermagem. http://www.corensp.org.br/resolucao293

[6] Mendes, K.D.S., Silveira, R.C.C.P. and Galvão, C.M. (2008) Revisão integrativa: Método de pesquisa para a incorporação de evidências na saúde e na enfermagem. Texto e Contexto Enfermagem, 17, 758. http://dx.doi.org/10.1590/S0104-07072008000400018

[7] Nunes, B.K. and Toma, E. (2013) Assessment of a Neonatal Unit Nursing Staff: Application of the Nursing Activities Score. Revista Latino-Americana de Enfermagem, 21, 348-355. http://dx.doi.org/10.1590/S0104-11692013000100009

[8] Wolff, L.D.G., Mazur, C.S., Wiezbicki, C., Barros, C.B. and Quadros, V. (2007) Dimensionamento de pessoal de enfermagem na unidade semi-intensiva de um hospital universitário de Curitiba. Cogitare Enferm, 12, 171-182.

[9] Inoue, K.C. and Matsuda, L.M. (2010) Sizing the Nursing Staff in an Intensive Care Unit for Adults. Acta Paulista de Enfermagem, 23, 379-384. http://dx.doi.org/10.1590/S0103-21002010000300011

[10] Fugulin, F.M.T., Rossetti, A.C., Ricardo, C.M., Possari, J.F. Mello, M.C. and Gaidzinski, R.R. (2012) Tempo de assistência de Enfermagem em unidade de terapia intensiva: Avaliação dos parâmetros propostos pela Resolução COFEN No. 293/04. Rev. Latino-Am. Enfermagem.

[11] Inoue, K.C. and Matsuda, L.M. (2009) Dimensionamento da equipe de enfermagem da UTI-Adulto de um hospital ensino. Revista Eletrônica de Enfermagem, 11, 55-63.

[12] Nicola, A.L. and Anselmi, M.L. (2005) Dimensionamento de pessoal de enfermagem em um hospital universitário. Revista Brasileira de Enfermagem, 58, 186-190. http://dx.doi.org/10.1590/S0034-71672005000200011

[13] Dal Bem, L.W. and Gaidzinski, R.R. (2007) Proposta de modelo para dimensionamento do pessoal de enfermagem em assistência domiciliária. Revista da Escola de Enfermagem da USP, 41, 97-103.

[14] Bonfim, D., Gaidzinski, R.R., Santos, F.M., Gonçales, C.S. and Fugulin, F.M.T. (2012) Identificação das intervenções de enfermagem na Atenção Primária à Saúde: Parâmetro para o dimensionamento de trabalhadores. Revista da Escola de Enfermagem da USP, 46, 1462-1470. http://dx.doi.org/10.1590/S0080-62342012000600025

[15] Dochterman, J.M. and Bulechek,G.M. (2008) Classificação das Intervenções de Enfermagem (NIC). Artmed, Porto Alegre.

[16] Bordin, L.C. and Fugulin, F.M.T. (2009) Distribuição do tempo das enfermeiras: Identificação e análise em Unidade Médico-Cirúrgica; Distribución del tiempo de las enfermeras: Identificación y análisis en una Unidad Médico Cuirúrgica. Revista da Escola de Enfermagem da USP, 43, 833-840.

http://dx.doi.org/10.1590/S0080-62342009000400014 
[17] Gaidzinski, R.R., Fugulin, F.M.T., Peres, H.H.C., Castilho, V., Massarollo, M., Mira, V.L., Pereira, I.M. and Tsukamoto, R. (2009) Dimensionamento informatizado de profissionais de enfermagem: Inovação tecnológica. Revista da Escola de Enfermagem da USP, 43, 1314-1319. http://dx.doi.org/10.1590/S0080-62342009000600029

[18] Telles, S.C.R. and Castilho, V. (2007) Custo de pessoal na assistência direta de enfermagem em unidade de terapia intensiva. Revista Latino-Americana de Enfermagem, 15, 1005-1009. http://dx.doi.org/10.1590/S0104-11692007000500019

[19] Cullen, D.J., Civetta, J.M., Briggs, B.A. and Ferrara, L.C. (1974) Therapeutic Intervention Scoring System: A Method for Quantitative Comparison of Patient Care. Critical Care Medicine, 2, 57-60. http://dx.doi.org/10.1097/00003246-197403000-00001

[20] Tranquitelli, A.M. and Ciampone, M.H.T. (2007) Número de horas de cuidados de enfermagem em Unidade de Terapia Intensiva de Adultos. Revista da Escola de Enfermagem da USP, 41, 371-377. http://dx.doi.org/10.1590/S0080-62342007000300005

[21] Costa, J.A. and Fugulin, F.M.T. (2011) Atividades de enfermagem em centro de material e esterilização: Contribuição para o dimensionamento de pessoal. Revista Latino-Americana de Enfermagem, 24, 249-256.

http://dx.doi.org/10.1590/S0103-21002011000200015 
Scientific Research Publishing (SCIRP) is one of the largest Open Access journal publishers. It is currently publishing more than 200 open access, online, peer-reviewed journals covering a wide range of academic disciplines. SCIRP serves the worldwide academic communities and contributes to the progress and application of science with its publication.

Other selected journals from SCIRP are listed as below. Submit your manuscript to us via either submit@scirp.org or Online Submission Portal.
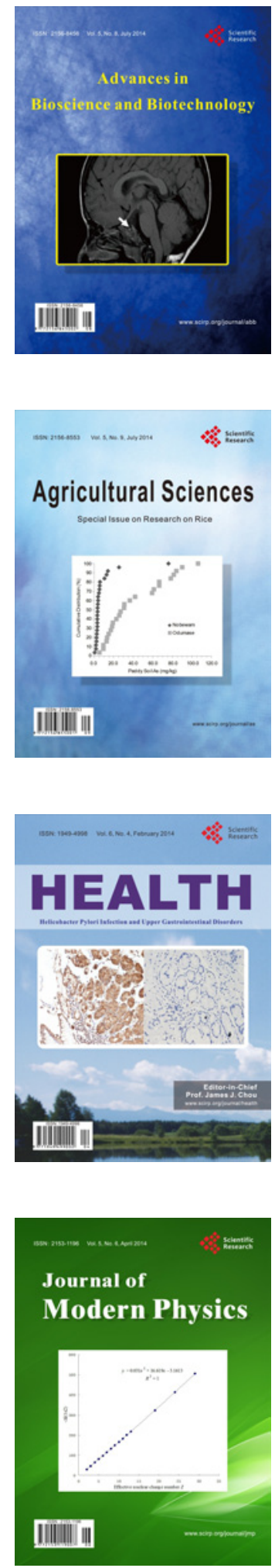
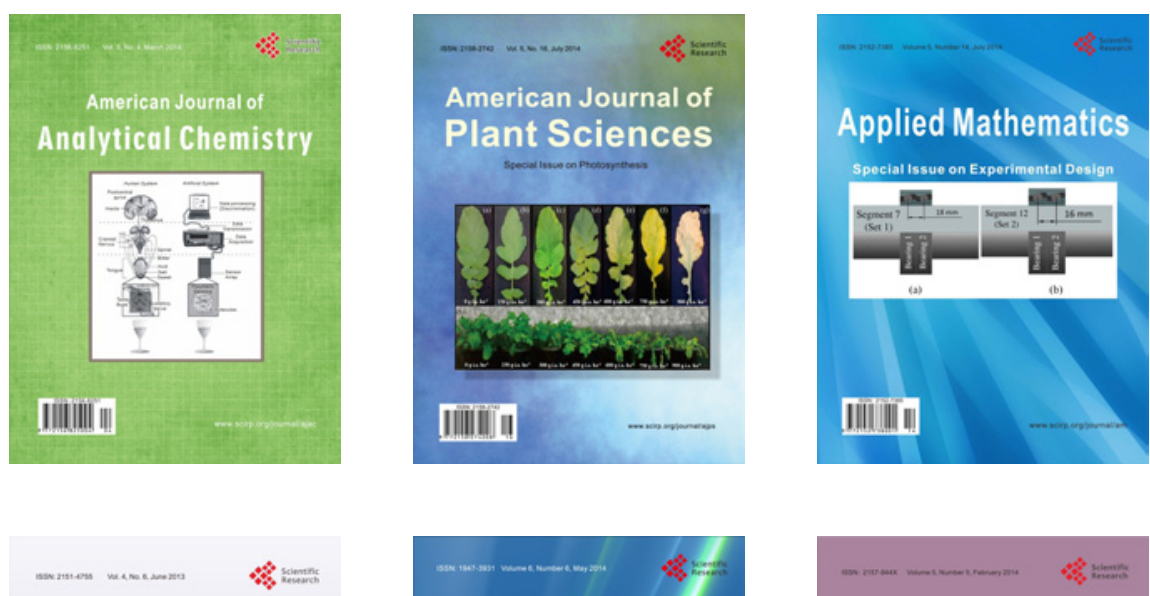

Creative Education
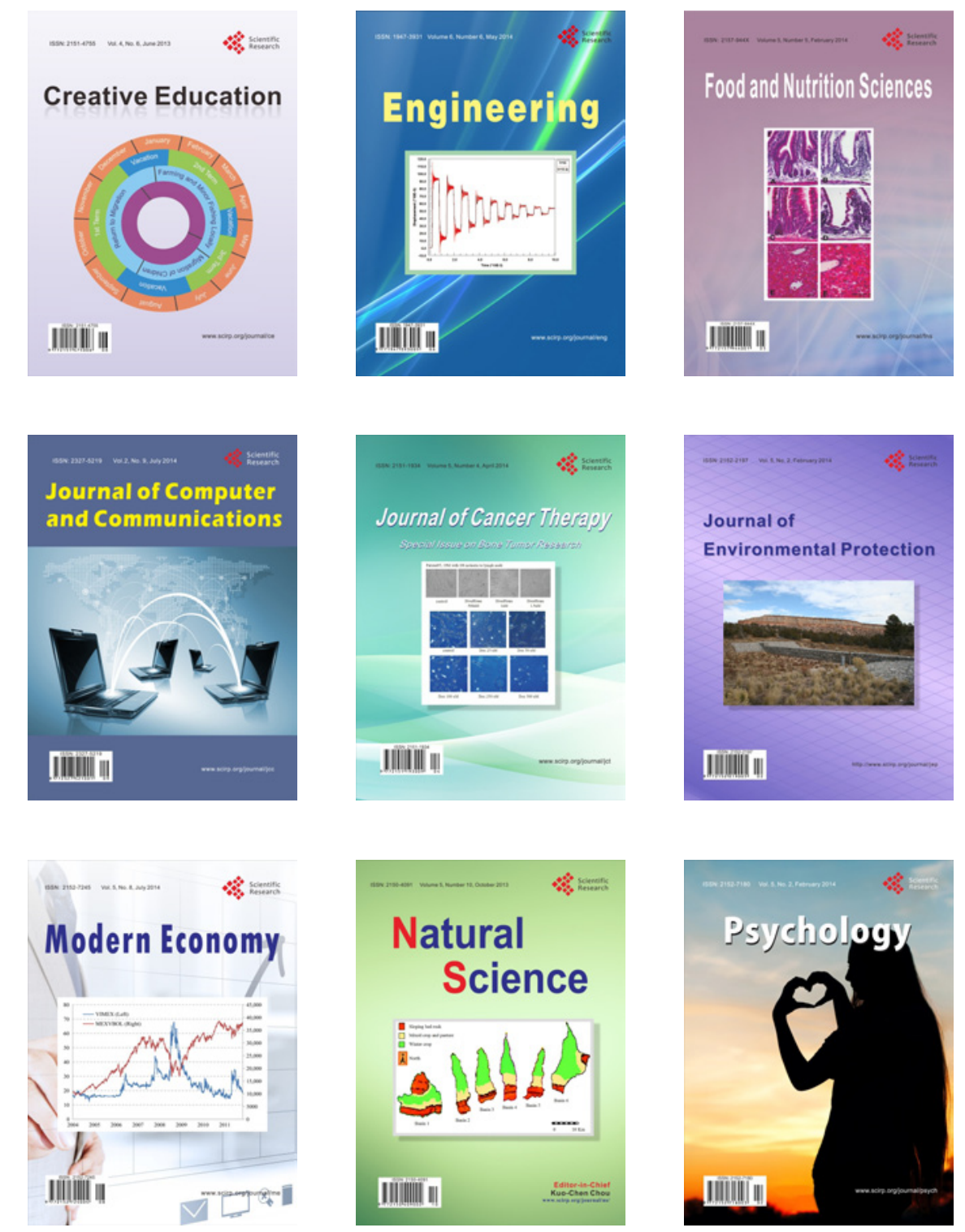